\title{
THE IMPACT OF ADIPOSITY ON SERUM ANTI-MULLERIAN HORMONE IN NORMAL AND OVERWEIGHT WOMEN WITH DECREASED OVARIAN RESERVE
}

\author{
Dragos Albu 1,2, Raluca Tulin 1,2, Alice Albu 1,2,3 \\ 1 „Carol Davila” University of Medicine and Pharmacy; 2 Medlife Hospital, Maternal-fetal and Reproductive \\ Medicine Department, 3 Elias Hospital, Endocrinology Department
}

Introduction: Few previous studies suggested a negative impact of obesity on antimullerian hormone (AMH) serum levels in patients with decreased ovarian reserve, but the data regarding the relationship between $\mathrm{AMH}$ and adiposity in the same category of patients without severe excess of body weight are scarce.

Aim: The aim of the study was to evaluate the relationship between AMH serum levels and body mass index in normal weight and overweight patients with reduced ovarian reserve.

Material and methods: patients were 196 infertile women with reduced ovarian reserve defined as $\mathrm{AMH} \leq 1 \mathrm{ng} / \mathrm{ml}$ evaluated in a Department of Assisted Reproduction between January 2007 and January 2014. Inclusion criterion was BMl $\leq 30 \mathrm{~kg} / \mathrm{m} 2$. Weight, height, age were recorded and $\mathrm{AMH}$ was measured in all the patients.

Results: Mean age of the study group was $36.9 \quad 4$ yrs and mean BMI $21.8 \quad 2.8 \mathrm{Kg} / \mathrm{m} 2(170$ normal weight patients and 26 overweight patients). Serum AMH was negatively correlated with age $(r=-0.154, p<0.05)$ and $\mathrm{BMI}(r=-0.147, p<0.05)$ when the entire group was analyzed, but the correlation was lost when only normal weight women were included in analysis. In a multivariate linear regression model both age $(p<0.0001)$ and BMI $(p=0.017)$ were independently associated with serum AMH.

Multivariate linear regression with $\mathrm{AMH}$ as dependent variable

$\begin{array}{llrrr} & \text { B } & \text { Std. Error } & \text { Beta } & \text { P value } \\ \text { BMI } & -0,122 & 0,035 & -0,211 & 0,017 \\ \text { Age } & -0,156 & 0,005 & -0,234 & 0,0001\end{array}$
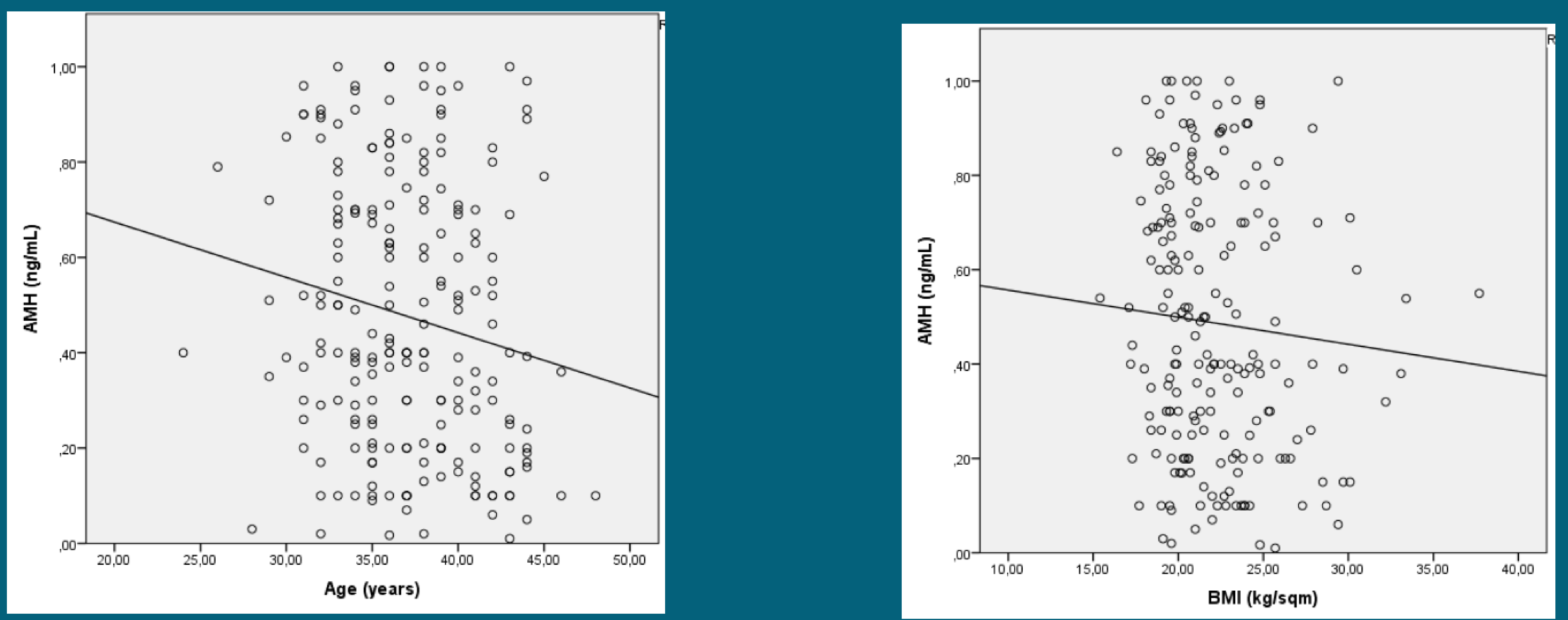

Conclusion: we found that in women with decreased ovarian reserve there is a negative impact of only slightly increased adiposity on serum AMH and this effect is independent of age. 